\title{
A Propaganda da AIB e suas Aproximações com a Propaganda Nazista
}

\author{
Edson José Perosa Junior ${ }^{1}$
}

\begin{abstract}
Resumo: Muito se foi discutido sobre o caráter fascista da AIB e atualmente existe um quase consenso de que o Integralismo foi, de fato, um movimento do gênero fascista. Partindo desse pressuposto, defendido por Hélgio Trindade (entre outros autores), podemos estabelecer várias semelhanças entre os métodos, técnicas e temas da propaganda nazista e integralista e de como a primeira pode ter influenciado a segunda. Analisando a "Revista Ilustrada Anauê"' é perceptível que os temas ali abordados estabelecem muitas relações com os temas apresentados em pôsteres e jornais da Alemanha nazista (disponíveis no German Propaganda Archive). Não pretendemos aqui uma simplificação e aproximação grosseira entre a propaganda nacional-socialista e a integralista, mas apenas ressaltar como ambas apresentam elementos em comum, que é um reflexo do caráter fascista da AIB, levando em conta as diferenças de contexto desses dois movimentos.
\end{abstract}

Palavras-chave: Revista Anauê, Plínio Salgado, Joseph Goebbels, Anticomunismo, Fascismo.

\section{A AIB em seu Contexto}

Os Anos 1920 e 1930 foram um período conturbado da história brasileira, onde o país passou por várias transformações

${ }^{1}$ Graduando do curso de História da Universidade Estadual de Maringá, sob orientação de João Fábio Bertonha. 
políticas, culturais e econômicas. Com a crise de 1929 o modelo agrário-exportador começa a entrar em crise e tem-se início a efetiva industrialização brasileira. Juntamente com o processo de industrialização iniciado nesse período, eclodem as lutas sociais. A Revolução de 1930 põe um fim na Primeira República e inicia-se a era Vargas. É nesse contexto que surge a Ação Integralista Brasileira (AIB) em 1932 (TRINDADE, 1979, p. 8).

A figura central no integralismo é a de Plínio Salgado, que participou da Semana de Arte Moderna em 1922 e incorporou muito dos pensamentos daquela década na formulação de suas próprias idéias. A participação de Salgado na Semana de Arte Moderna foi modesta, todavia foi de grande importância para ele, pois reforçou algumas de suas idéias. Plínio Salgado fez parte do movimento cultural decorrente da Semana de Arte Moderna que ficou conhecido como Grupo Anta, que tinha por característica o ufanismo e a exaltação do país. Também faziam parte desse grupo Menotti Del Picchia e Cassiano Ricardo, o grupo tinha o nome de anta, pois havia escolhido o animal homônimo como seu símbolo, que para eles tinha uma função mística na cultura tupi. Esse grupo tinha uma orientação política claramente de direita.

Mais importante do que a sua experiência nos partidos políticos (Salgado fez parte do Partido Republicano Paulista) foi a 
influência da revolução literária sobre a evolução ideológica de suas concepções (TRINDADE, 1979, p. 42). Plínio Salgado sempre foi muito marcado pela religiosidade e pelo nacionalismo desde sua infância no interior de São Paulo. Em 1930 se desligou do PRP e partiu em uma viagem à Europa, que foi de fundamental importância para o aprimoramento de seu pensamento:

A viagem à Europa deu a Plínio Salgado a oportunidade de meditar sobre a sua obra e sobre a política brasileira e de ler boa parte da literatura política que circulava no velho mundo naquele momento. Mais importante, porém, foi a sua passagem pela Itália, onde conheceu de perto o Fascismo, que o maravilhou e o estimulou a pensar na criação de algo semelhante no Brasil. (BERTONHA, 2006, p. 61)

Assim podemos perceber como na sua evolução ideológica Plínio Salgado recebeu influência do Fascismo Italiano e do Movimento Modernista (vale lembrar que a semana de 1922 expressou diversas tendência e que a de Plínio Salgado é apenas uma delas). No cerne da ideologia integralista estava a idéia de "revolução do espírito", que seria uma "revolução interior" no povo brasileiro que iria anunciar uma nova era. O integralismo se apresentava fundamentalmente como um movimento de cultura, que era contra o sistema político vigente no país e contra o partidarismo, 
daí a aversão da AIB de se mostrar como um partido político (CAVALARI, 1999, p. 41).

Em 1932 muitos dos temas dominantes da ideologia integralista já estão presentes, ainda que de forma genérica e até mesmo imprecisa. $O$ antiliberalismo e o nacionalismo já se encontram ostensivamente presentes nesse período, enquanto a organização do Estado permanece muito vaga ainda. A concepção de um humanismo espiritualista é a principal baliza do pensamento integralista, que se define em sua contraposição ao materialismo comunista e burguês (TRINDADE, 1979, p. 86).

$\mathrm{O}$ integralismo considera de fundamental importância a obediência e a disciplina, condição sine qua non para a obtenção da ordem espiritual e moral. Na AIB era exigido de seus membros um juramento de fidelidade e obediência ao integralismo e ao Chefe Nacional, Plínio Salgado (CAVALARI, 1999, p. 52). Os integralistas eram instruídos a nunca contestar as ordens de um superior e jamais comentar as decisões do Chefe Nacional, do militante esperava-se apenas que seguisse à risca das diretrizes e ordem. Nesse ponto é muito clara a proximidade do integralismo com outros movimentos fascistas e autoritários em geral. Hitler exigia de seus seguidores apenas a obediência absoluta e clamava autoridade absoluta sobre o partido. Foram nesses termos de autoritarismo e obediência cega ao 
Cadernos de Clio, Curitiba, n. ${ }^{\circ} 2,2011$

Führer que o Partido Nacional-Socialista dos Trabalhadores Alemães foi refundado em 27 de fevereiro de 1925, depois de um período de marginalidade política (BYTWERK, 2008, p. 15).

Como já foi dito anteriormente os anos 1930 é um período intensamente agitado na política e na sociedade brasileira, pois o país passa por importantes transformações. O clima é de tensão e polarização política entre grupos de extrema esquerda e de extrema direita, assim como ocorreu em outras partes do mundo no mesmo período. A democracia liberal e suas instituições estão sendo contestadas em várias partes do mundo. $\mathrm{O}$ fascismo e o comunismo apresentam-se como alternativas ao sistema liberal ainda vigente:

A influência da expansão das idéias fascistas européias faz da década de 30 no Brasil um período de ascensão de idéias radicais de direita. Este fato de constata pela presença nas livrarias de uma abundante literatura sobre o fascismo italiano e o novo Estado português. A publicação, neste período, de uma série de livros analisando a situação política brasileira numa perspectiva antiliberal, bem como o aparecimento de várias revistas e movimentos ideológicos de orientação política fascista, monarquista ou corporativista, comprovam a receptividade das idéias autoritárias na década de 1930. A importância desses grupos é desigual e sua ação revela uma predisposição influenciar ideologicamente o Governo Provisório. Mais tarde, a maior parte desses grupos políticos ou intelectuais vai se amalgamar na Ação Integralista Brasileira. (TRINDADE, 1979, p. 97) 
Destarte, o integralismo foi uma força aglutinadora das tendências de extrema direita no Brasil dos anos 1930. Entre 1932 e 1933 o integralismo vagarosamente foi se organizando e consolidando no cenário político brasileiro e somente em 1934 ganhou corpo e uma maior força política (BERTONHA, 2006, p. 61). A propaganda ocupa, no integralismo, uma posição de suma importância, pois era o meio pelo qual o movimento arregimentava novos militantes e mantinha a coesão dos já integrados ao movimento. Especificamente a palavra impressa (livros, jornais e revistas) era o principal interlocutor entre a doutrina integralista e o militante (CAVALARI, 1999, p. 79). Não obstante, a propaganda integralista compartilhou muitos temas e métodos com a propaganda nazista, o que demonstra o caráter fascista da AIB e suas ligações com os fascismos europeus. Todavia isso não significa que o integralismo era um mimetismo dos fascismos da Europa, especificamente o italiano e o alemão.

\section{A Revista Ilustrada Anauê}

Em janeiro de 1935 foi publicada pela primeira vez a Revista Ilustrada Anauê. Foi uma publicação mensal que teve o total de 21 edições, sendo a última publicada em 1937. A Revista era vendida e circulava tanto entre os membros da AIB, quanto entre o 
público em geral; era uma Revista que visava conquistar adeptos para o integralismo, por isso se utilizava de uma linguagem e um formato atraente para o grande público, publicando várias imagens. A primeira edição apresentava-se " com o objetivo de divulgar, em linguagem acessível a todos, a doutrina integralista" (ANAUÊ, n. I). Desta forma, a revista colimava atingir a todos os militantes, por mais básica que fosse sua instrução, e como forma de divulgar a doutrina do sigma. Já podemos perceber aqui uma semelhança clara com os métodos de propaganda nazista:

Hitler considerava que a propaganda sempre deveria ser popular, dirigida às massas, desenvolvida de modo a levar em conta um nível de compreensão dos mais baixos. "As grandes massas", dizia ele, "têm uma capacidade de recepção muito limitada, uma inteligência modesta, uma memória fraca'. Por isso mesmo, a propaganda deveria restringir-se a pouquíssimos pontos, repetidos incessantemente. Se eram muitos os inimigos a serem atacados, para não dispersar o ódio das massas seria preciso mostrar que eles pertenciam a mesma categoria, não ficando assim individualizado o adversário. (LENHARO, 1986, p. 47-48)

Nesse sentido a propaganda da AIB foi muito próxima dessa premissa da propaganda nazista, tanto apregoada por Goebbels e Hitler. Não obstante, os símbolos desses movimentos (a suástica, o sigma), são também “imagens", pois visam reduzir os conceitos e 
problemáticas e dessa forma conduzindo os militantes para a ação (BERTONHA, 2008, p. 259). Portanto tanto o integralismo quanto o nazismo, apelavam para a ação efetiva dos militantes, prescindindo da reflexão sobre suas ações. Os militantes deveriam apenas obedecer e agir segundo as intenções do líder supremo e a propaganda que era apregoada pelo nazismo e o integralismo objetivavam induzir os militantes nesse sentido.

A especificidade da Revista Anauê é que foi uma revista que se utilizava abundantemente de fotografias, diferentemente da maioria dos outros periódicos integralistas. As imagens eram utilizadas para atestar a realidade e a grandeza do movimento integralista. As fotografias eram recursos de linguagem, pois apelavam diretamente na doutrinação dos brasileiros "semianalfabetos", ou seja, os menos instruídos que não liam os livros da doutrina integralista (BULHÕES, 2007, p. 55). Assim a ideologia do movimento deveria ser simplificada para que os brasileiros menos "cultos" pudessem compreender o integralismo e serem cooptados por ele.

Compreendia-se muito bem do poder de convencimento que uma fotografia poderia ter, já que ela era e é tida por muitos como um retrato fiel da realidade. Logo se tornava essencial para a propaganda política o uso de fotografias devido ao seu poder de

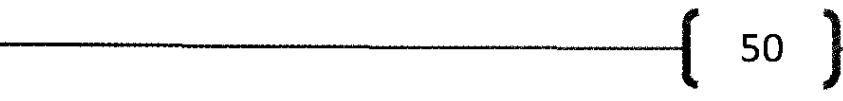


convencimento inerente. $\mathrm{Na}$ revista Anauê se utilizavam as fotografias para atestar a realidade e concretude do movimento e comprovar como esse era genuinamente brasileiro - isso se fazia principalmente através das imagens de comícios e marchas nas mais diversas cidades brasileiras (BULHÕES, 2007, p. 55). Pode-se notar também que o uso das fotografias na revista vai se aprimorando tecnicamente ao longo dos anos de sua existência, já que a disposição das fotografias na revista se modifica ao longo de suas edições. Como podemos notar por essa fotografia da Revista, em que mostra jovens enfileirados e ao lado uma citação de Plínio Salgado, como que para atestar a sincronia entre os militantes e o líder:

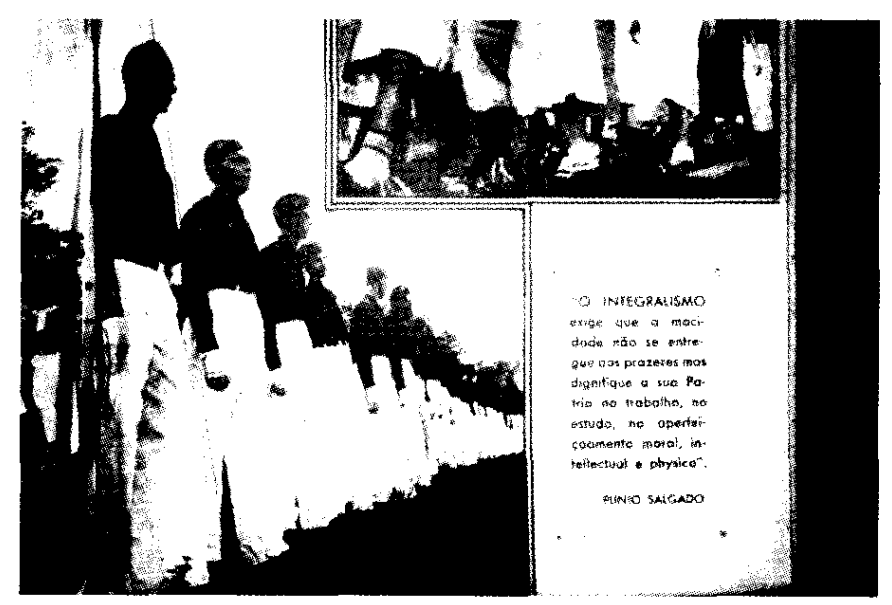

(ANAUÊ, n. VII de 10/05/1936). 
A fotografia era usada também como uma arma política contra os inimigos da AIB. Por meio da fotografia a Revista Anauê construía e divulgava a imagem de seus inimigos e qualificavam seus adversários como sendo perigosos, sujos, traiçoeiros, covardes, etc. Todavia eles não eram apresentados como sendo seus adversários políticos, era mais comum ver os inimigos da AIB definidos como “inimigos da pátria" ou "inimigos da Igreja”. Os ditos inimigos eram por vezes demonstrados de maneira caricatural, fazendo alusões a determinados animais ou insetos, geralmente para enfatizar a repugnância dos judeus ou dos comunistas (BULHÕES, 2007, p. 99 e 100). A Revista atacava veementemente aquilo que considerava como inimigos da pátria e utiliza-se de uma linguagem simples, tentando deixar da forma mais clara e simples possível para o leitor quem estava atacando.

Era muito comum a Revista Anauê trazer em suas edições fotos de desfiles da AIB nas mais diversas cidades do país, como na edição número um, em que são apresentadas fotos de um desfile integralista em Curitiba no Paraná, onde se vê as fileiras integralistas perfeitamente alinhas e uniformizadas demonstrando a unidade e a força do movimento. Destarte, essas fotografias transmitiam uma idéia muito clara na ideologia do integralismo, que era a noção de unidade, irmandade e igualdade entre os integralistas. Pela foto 
Cadernos de Clio, Curitiba, n. ${ }^{\circ} 2,2011$

abaixo podemos perceber como a AIB tencionava transmitir a imagem de igualdade e confraternização entre os seus integrantes, além de demonstrar como o Integralismo estava preocupado com a educação de suas crianças:

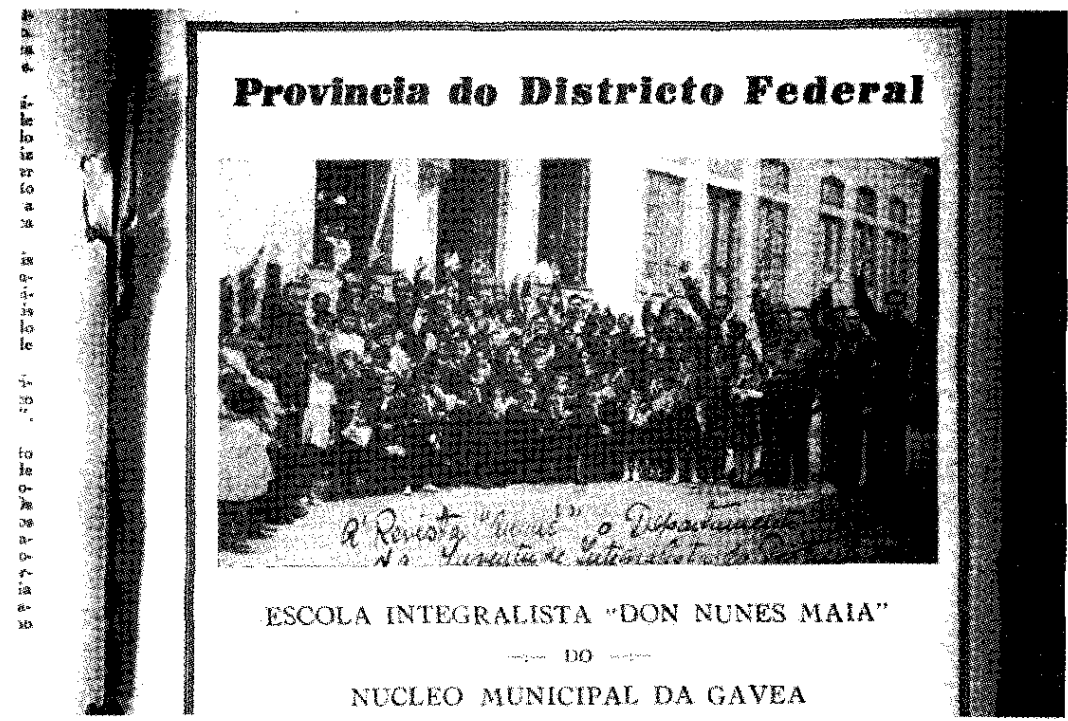

(ANAUÊ, n. I de 01/01/1935).

As doutrinas essenciais aos movimentos fascistas eram muito presentes na Revista Anauê, que pretendia combater o liberalismo, a democracia, o comunismo, dentro outros inimigos. Dessa forma o integralismo - e o fascismo em geral - se apresentava como alternativa para a sociedade brasileira em crise do período: 
Cadernos de Clio, Curitiba, n. ${ }^{\circ}$ 2, 2011

Uma das alternativas encontradas para resolver tais dilemas foi $o$ apelo às soluções nacionalcorporativistas: o fascismo. Ele foi, em geral, uma doutrina radical e nova, mas seus fundamentos básicos - nacionalismo, racismo, corporativismo - estavam presentes na cultura européia e no capitalismo a muito tempo. A doutrina fascista foi a reelaboração dessas velhas tradições políticas e sociais de forma a dar conta dos novos problemas e condições da prática política do século $\mathrm{XX}$. Os pensadores fascistas objetivavam criar um novo homem em uma nova sociedade, expurgada do liberalismo, da decadência burguesa e do perigo do materialismo marxista; uma sociedade sem divisões, coesa e solidária. (BERTONHA, 2008, p. 264)

Esse discurso estava no cerne da propaganda integralista da mesma forma que estavam presentes na propaganda nazista, resguardadas as devidas nuanças. Na Revista Anauê de número três, a simpatia de, pelo menos, parte do movimento pelo nazismo se explicita em um artigo intitulado "raça e política" onde o autor enaltece a "nova Alemanha" pela sua política racial já que "a aversão contra a idéia racista só se explica pela hábil e sistemática difamação que especialmente interessados promoveram contras as concepções racistas e, visando, sobretudo as da nova Alemanha", (ANAUE, n. III).

Outro tema freqüente da revista era o anticomunismo, que era um dos pilares da doutrina integralista. A Revista Anauê de número onze apresenta os "dez mandamentos dos comunistas", 
neles os comunistas são descritos como ateus, ladrões, malfeitores que querem destruir a família, o cristianismo e tudo que há de "bom" no mundo. Os mandamentos são: "Odiar o Senhor, vosso Deus; amaldiçoar vosso Deus e Senhor; desprezar o dia do Senhor; desprezar pai e mãe; matar; impureza; furtar; mentir; desejar a mulher do próximo; preparar a revolução universal" (ANAUÊ, n. XI). Concomitantemente a revista chamava a atenção para o "perigo vermelho" e a necessidade de combater o comunismo no Brasil e no mundo.

Da mesma forma que no nazismo, a propaganda integralista soube explorar o medo de uma "revolução bolchevique", que desde a Revolução Russa assustava e alarmava as elites brasileiras. A propaganda nazista intensificou sua campanha antimarxista a partir de 1936, mirando na paranóia anticomunista já bem enraizada em setores da sociedade alemã da época (WELCH, 2002, p. 83). Dessa forma, a propaganda, seja nazista ou integralista, foi direcionada para explorar e exacerbar temores já existentes na sociedade.

Assim que os nazistas chegaram ao poder em 1933 houve intenso esforço para controlar os meios de comunicação. $O$ controle dos meios de comunicação não se deu do dia para a noite, foi preciso certo tempo para que Goebbels e o recém criado Ministério da Propaganda, efetivamente, controlassem a maior parte dos meios de 
comunicação na Alemanha (WELCH, 2002, p. 37). A propaganda, diferentemente do que o senso comum imagina, raramente cria um estado de espírito novo na opinião pública, o que ela faz é, geralmente, explorar as tendências já presentes na opinião pública de forma que lhe melhor interessa. É importante destacar a importância da opinião pública nas formulações de propagandas que objetivavam e expressavam temas correntes e aceitos por grande parte da população e não analisar apenas o aspecto organizativo da propaganda nazista ou integralista, mas a reação da opinião pública a propaganda. A propaganda não era pensada no vazio, se tinha em mente quais eram os principais anseios e frustrações presentes na população em geral e se imaginavam méis engenhosos de explorar esses anseios e frustrações (WELCH, 2002, p. 59).

$\mathrm{O}$ integralismo pretendia fazer-se presente em todos os momentos da vida de seus militantes, mesmo nos mais íntimos. Apenas assim os membros da AIB estariam plenamente direcionados na doutrina do sigma, dessa maneira o integralismo colimava manter a coesão e a camaradagem entre todos os membros do movimento, através dos mais variados rituais e cerimônias:

Os rituais eram ainda mais preciosos para o integralismo. Eles celebravam a força e o poder do movimento e transmitiam a seus adeptos a ideologia integralista. Para esse fim, toda a ocasião era 
Cadernos de Clio, Curitiba, n. ${ }^{\circ} 2,2011$

aproveitada: casamentos, batizados, funerais. A Ação Integralista Brasileira tinha minuciosos rituais para cada ocasião e também para as reuniões em suas sedes e para o encontro com os líderes (BERTONHA, 2006, p. 67)

Portanto os símbolos e rituais tinham um papel primordial a ser desempenhado dentro do universo integralista e fascista em geral. A tendência era usar símbolos e indumentárias como forma de conduzir e inspirar as massas para um fim determinado. As sessões doutrinárias da AIB eram repletas desses símbolos e rituais que expressavam a ideologia do movimento. Essas exterioridades são a forma mais óbvia e fácil de identificar os movimentos fascistas como sendo pertencentes de uma mesma família, pois todos os fascismos se utilizaram de rituais, símbolos e indumentárias em larga escala:

\begin{abstract}
Os símbolos e ritos, estratégias de padronização e unificação do integralismo, responsáveis por criar, junto aos militantes, a "mística" do movimento, constituíam-se também em eficiente estratégia de arregimentação de novos adeptos. Desempenhavam, portanto, no interior da AIB, uma dupla função: unificavam e arregimentavam. (CAVALARI, 1999, p. 163-164)
\end{abstract}

Ao longo da existência da Revista Anauê, a utilização de fotografias e de fotomontagens vai aumentando e aprimorando-se cada vez mais, demonstrando que a revista coadunava-se com as 
inovações técnicas dessa área. As fotografias passam a dominar a revista e diminui-se o uso de letras manuscritas, passando-se a usar mais frequentemente letras de imprensa. $O$ crescimento do movimento explica em grande parte essa evolução gráfica da revista, pois o movimento passa a cooptar vários jornalistas, inclusive jornalistas renomados da época. O aumento da arrecadação da AIB também favoreceu para esse aprimoramento da Revista Anauê (BULHÕES, 2007, p. 76-77).

Tal como no nacional-socialismo a AIB também tem a pretensão de criar, difundir e controlar as atividades artísticas e culturais da nação. Não se admitia que existissem atividades artísticas, opostas ou contraditórias, a mundividência integralista. Para isso a Ação Integralista Brasileira criou órgão e departamentos específicos para lidar e controlar a produção cultural (no caso o Departamento de Cultura Artística). Esse órgão era responsável para criar uma arte verdadeiramente nacional e inspirada na "genuína" cultura brasileira e que apresentasse e corporificasse o ideal da nação brasílica (TRINDADE, 1979, p. 186).

\section{Conclusão: O Caráter Fascista da AIB}

Os movimentos fascistas em geral, e o integralismo em particular, desejavam mudar as práticas mais prosaicas nas atividades 
humanas, como substituir o aperto de mão burguês pela saudação fascista (antiga saudação romana, adotada, grosso modo da mesma forma, pelos mais diversos movimentos fascistas). Esses regimes e movimentos acreditavam assim poder modificar as formas de comportamento entre as pessoas, o que se mostrou, obviamente, um fracasso no sentido geral, ainda que conseguindo alguns sucessos localizados (FALASCA-ZAMPONI, 2008, p. 63-64).

A propaganda e a organização da AIB eram voltadas para propiciar a socialização político-ideológica dos militantes, futuros membros do Estado Integralista. Essa difusão doutrinária estabelecia uma série de mecanismos para a transmissão de valores, símbolos e comportamentos que deveriam ser a realização do futuro Estado Integralista. Principalmente deveria se criar o hábito da obediência aos desígnios do Chefe Nacional e o acatamento de suas ordens. A semelhança com o fascismo europeu é muito clara, pois o nazismo e o fascismo italiano tinham projetos muito semelhantes para seus povos, ainda que fosse um tanto diferente em seus conteúdos, o objetivo era basicamente o mesmo:

Os dirigentes integralistas, conscientes de importância dos "agentes socializadores", desenvolvem-nos minuciosamente, inspirados nos movimentos fascistas europeus. A tarefa fundamental era criar o hábito da obediência aos chefes e a submissão às estruturas autoritárias. Portanto, não se tratava, como pretendia 
Cadernos de Clio, Curitiba, n. ${ }^{\circ}$ 2, 2011

alguns dirigentes integralistas, se simplesmente copiar "certas formas exteriores do fascismo", mas de adotar os mecanismos básicos da formação totalitária fascista. (TRINDADE, 1979, p. 188).

Ainda assim não se pode reduzir o integralismo como sendo um mero mimetismo dos movimentos fascistas europeus. $\mathrm{O}$ integralismo é fruto da conjuntura política, econômica, social e cultural do Brasil dos anos 1930. Foi apenas nesse contexto de crise que o integralismo se tornou uma opção política viável para um número significativo de brasileiros. O integralismo não nasceu também da visão de um homem apenas, houve uma confluência de idéias autoritárias de extrema direita encabeçadas por diversas figuras públicas (TRINDADE, 1979, p. 277). Não se pode negligenciar, porém, o contexto externo marcado pela revolução russa e pela ascensão do fascismo na Europa, o Brasil, inevitavelmente, sofreu influência das mais diversas provenientes do exterior.

Ao analisar a propaganda integralista fica evidente a sua aproximação com o fascismo europeu em geral, e o nazismo em particular (ainda que a influência do fascismo italiano fosse provavelmente maior). Os temas $\mathrm{e}$ as técnicas utilizadas na propaganda integralista são evidentemente semelhantes às utilizadas 
pelo nazismo, resguardadas a suas proporções distintas, já que o nazismo dispunha de todo a aparelho do Estado para elaborar e difundir a propaganda, assim a propaganda do partido era também a propaganda do Estado. Os formatos e as roupagens que a propaganda integralista assume são próximos da propaganda nazista, mas não deve ser essa a principal baliza de comparação e sim os objetivos políticos e ideológicos que esses dois fascismos propunham para suas respectivas sociedades, e ai também as semelhanças entre o integralismo e os fascismos europeus ficam patentes (BERTONHA, 2008, p. 262).

Portanto, a propaganda integralista apresenta diversas semelhanças com os métodos e temas utilizados pela propaganda nazista. Os integralistas, assim como os nazistas, tentaram utilizar todos os meios disponíveis para divulgar a sua propaganda (fazendo inclusive alguns filmes), todavia o nazismo dispunha, a partir de 1933, do aparato do Estado para propagandear a sua ideologia, enquanto o integralismo nunca chegou ao poder. $\mathrm{O}$ anticomunismo, $\mathrm{o}$ antiliberalismo, o anti-semitismo estão presentes nestes dois movimentos, resguardadas as suas devidas proporções (o antisemitismo é, sem dúvida, imensamente mais importante no nazismo do que no integralismo). As nuanças entre o nazismo e o integralismo também devem ser ressaltadas, já que no integralismo o 
catolicismo tem uma maior influência e no nazismo é quase nulo, além de outras nuanças ideológicas. Dessa maneira, ao analisarmos a propaganda integralista e nazista o pressuposto de que o integralismo é um fascismo é reforçado, já que são conspícuas as semelhanças entre esses dois movimentos e poucas as suas diferenças.

\section{Referências Bibliográficas}

BERTONHA, João Fábio. Fascismo, Nazismo, Integralismo. São Paulo: Ática, 2006.

BERTONHA, João Fábio. Sobre a Direita. Maringá: Eduem, 2008.

BYTWERK, Randall. Landmark Speeches of National Socialism. Texas: A\&M University Press, 2008.

BULHÕES, Tatiana da Silva. Evidências Esmagadoras dos Seus Atos: fotografias e imprensa na construção da imagem pública da Ação Integralista Brasileira (1932-1937). Niterói, Tese de Mestrado em História, UFF, 2007.

CAVALARI, Rosa Maria Feiteiro. Integralismo: ideologia $e$ organização de um partido de massa no Brasil (1932-1937). Bauru: Edusc, 1999.

LENHARO, Alcir. Nazismo: o triunfo da vontade. São Paulo: Ática, 1989. 
TRINDADE, Hélgio. Integralismo: o fascismo brasileiro na década de 30. São Paulo: Difel, 1979.

FALASCA-ZAMPONI, Simonetta. Fascismo e Estética. In:

Fascismos: conceitos e experiências. Rio de Janeiro: Mauad, 2008. p. $45-66$.

WELCH, David. The Third Reich: politics and propaganda. Londres: Routleadge, 2002.

\section{Periódicos:}

Revista Ilustrada Anauê (RJ)- Período Pesquisado: 1935- 1937 